TERRA. Revista de Desarrollo Local e-ISSN: 2386-9968

Número 9 (2021), 203-208

DOI 10.7203/terra.9.21512

IIDL - Instituto Interuniversitario de Desarrollo Local

\title{
Reseña. Trabajo social para tiempos convulsos. El camino hacia la ruptura epistemológica
}

\author{
Ane Ferran Zubillaga \\ Doctora por la Universidad de Deusto, Licenciada en Humanidades (empresa), \\ Diplomada en Trabajo Social. Docente en la Facultad de Ciencias Sociales y Humanas \\ de la Universidad de Deusto \\ aferran@deusto.es

\section{Cinta Guinot Viciano} \\ Doctora por la Universidad de Deusto, Licenciada en Antropolotía Social y Cultural, \\ Diplomada en Trabajo Social. Docente en la Facultad de Ciencias Sociales y Humanas \\ de la Universidad de Deusto \\ cguinot@deusto.es
}

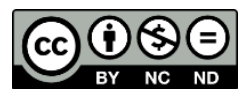

Esta obra se distribuye con la licencia Creative Commons

Reconocimiento-NoComercial-SinObraDerivada 4.0 Internacional 


\section{SECCIÓN RESEÑAS}

\section{Reseña. Trabajo social para tiempos convulsos. El camino hacia la ruptura epistemológica}

Resumen: La obra expone un diálogo lleno de matices, cuyo objetivo ha sido la búsqueda de una alternativa de práctica profesional del Trabajo Social. Un diálogo construido por los autores en el marco de un proceso participativo con profesionales de la práctica del Trabajo Social, cuyo objetivo ha sido analizar la viabilidad de las prácticas narrativas en contextos de práctica profesional del ámbito generalista de los servicios sociales. Es la narración de un camino emprendido hacia posturas epistemológicas posmodernas, posestructuralistas, con propuestas de prácticas constructivistas y construccionistas con lo que se pretende dar un giro metodológico que permita encontrar nuevas ubicaciones para responder a estos tiempos convulsos acontecidos a lo largo de estas primeras décadas del siglo XXI. Esta obra plantea una visión despatologizante de las personas consultantes de los servicios sociales proponiendo una intervención social que presta atención a sus relatos y experiencias, en la que se reconozcan sus capacidades, sus habilidades y en la que puedan recuperar la confianza perdida en ellas mismas. Una propuesta que vincula el trabajo social con la práctica narrativa, con un objetivo claro: proponer una alternativa para responder a profesionales que demandan un cambio en la manera de gestionar sus prácticas profesionales.

Palabras clave: trabajo social, práctica narrativa, epistemología, tesis doctoral.

Recibido: 08 de septiembre de 2021

Devuelto para revisión: -

Aceptado: 08 de septiembre de 2021

\section{Referencia / Citation:}

Ferran, A., y Guinot, C. (2021). Reseña. Trabajo social para tiempos convulsos. El camino hacia la ruptura epistemológica. TERRA. Revista de Desarrollo Local, (9), 203-208. DOI 10.7203/terra.9.21512 


\section{Amparo Martí Trotonda y José Vicente Pérez Cosín}

\section{TRABAJO SOCIAL PARA TIEMPOS CONVULSOS. EL CAMINO HACIA LA RUPTURA EPISTEMOLÓGICA}

Valencia (Esp). Ed. Publicaciones Universidad de Valencia (PUV), 2020, 405 pp.

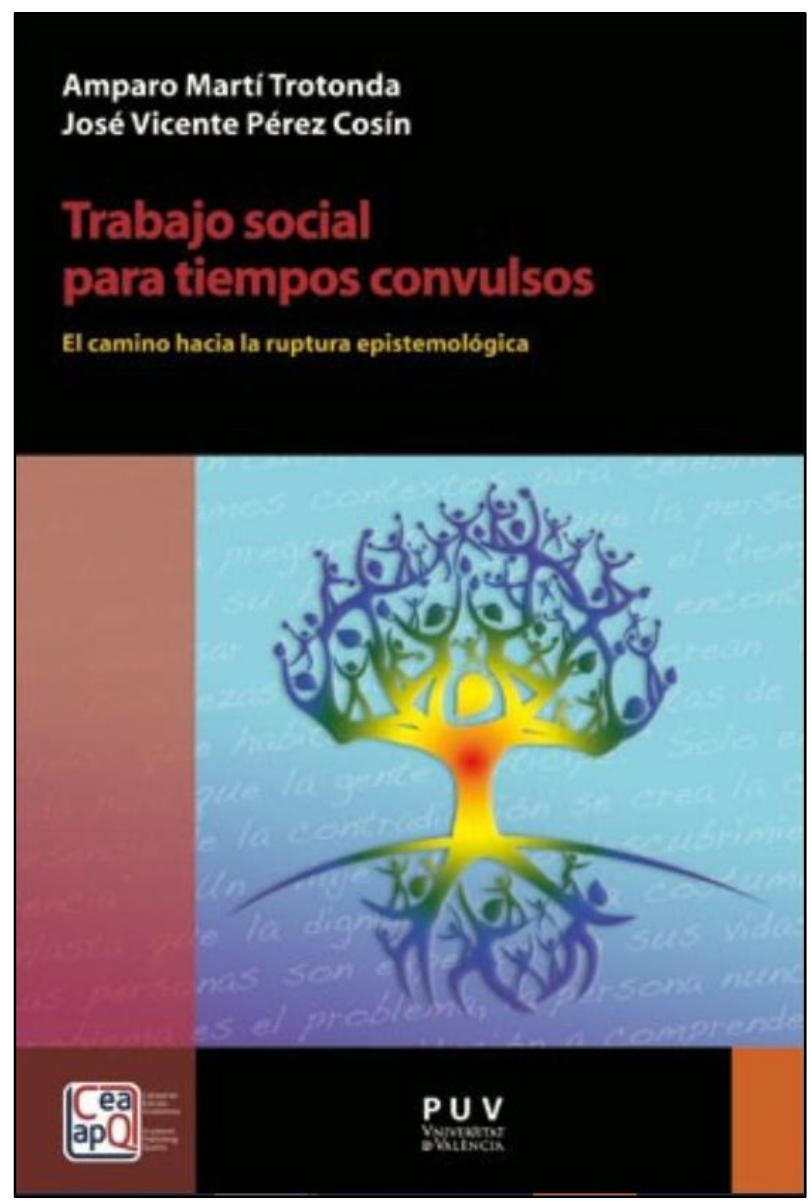

La obra que estamos reseñando es el resultado de la tesis doctoral de Amparo Martí, dirigida por el profesor José Vicente Pérez; una tesis doctoral premiada en el III Congreso Internacional de Facultades y Escuelas de Trabajo Social - CIFETS celebrado en la Universidad de Deusto, Bilbao, en 2018, signo visible de su gran calidad e importante aportación a nuestra disciplina.

La investigación trata de analizar la viabilidad de las prácticas narrativas en contextos de práctica profesional del ámbito generalista de los servicios sociales, desde el Trabajo Social, y sentar las bases de una nueva construcción profesional que tenga como paradigma central la Práctica narrativa

Para realizar la investigación se generó un espacio formativo colaborativo en la Universidad de Valencia, en el que participaron profesionales de la acción social del ámbito público y del tercer sector social (servicios sociales generalistas), además de docentes del área de trabajo social y servicios sociales de la universidad. Este espacio ha permitido la co-construcción del conocimiento desde lo empírico, en el marco de un proceso interactivo para dar una respuesta orientada a la búsqueda de la viabilidad del enfoque de la práctica narrativa en contextos públicos y generalistas para la acción social y en particular, para el trabajo social.

El libro recoge el relato de la experiencia compartida, de los conocimientos coconstruidos y de las conclusiones obtenidas, en una cuidada edición con apoyos visuales en forma de gráficos, tablas y figuras que facilitan, no solo la lectura del texto, sino, fundamentalmente, la comprensión del contenido presentado. Un contenido, siguiendo a White, rico y denso, que articula constantemente las aportaciones de autores referentes y los relatos de las dinámicas grupales y las entrevistas realizadas a las participantes en la investigación. En palabras de los autores, estamos ante la narración de un camino emprendido hacia posturas epistemológicas posmodernas, posestructuralistas, con propuestas de prácticas constructivistas y construccionistas. Se trata de un giro metodológico que responde a la necesidad de buscar nuevas ubicaciones para responder a estos tiempos convulsos acontecidos a lo largo de estas primeras décadas del siglo XXI. 
Tiempos convulsos, también para las trabajadoras sociales, a quienes la crisis social nos sorprendió en un momento en el que veníamos sintiendo cierto malestar en los servicios sociales. Así, A. Martí y J.V. Pérez fijan la mirada en las trabajadoras sociales que buscan alternativas que superen el desánimo, el alejamiento de la persona y permitan volver a situar en el centro de la acción a los sujetos consultantes.

La obra está estructurada en ocho capítulos: los tres primeros sitúan conceptualmente la propuesta de investigación. Los capítulos cuarto y quinto explican detalladamente la metodología de investigación. El capítulo sexto narra los resultados obtenidos y la discusión planteada a partir de los mismos. Por fin, los capítulos séptimo y octavo presentan la evaluación de la experiencia y las reflexiones finales. Veamos con un poco de detalle cada uno de los capítulos.

En el capítulo 1, los autores trazan un relato para situar la Práctica narrativa como modelo de intervención, en un intento bien logrado, en nuestra opinión, de reubicarse profesionalmente en la posmodernidad, identificando territorios que ayuden a generar respuestas a las preguntas reformuladas desde la práctica narrativa. Para ello, buscan una nueva senda partiendo de la identificación de otras esferas para la práctica social, apostando por el paradigma de la posmodernidad e identificando los paralelismos existentes entre la práctica narrativa y el trabajo social. A continuación, fijan la mirada en las bases de la práctica clínica y los aprendizajes construidos desde ella, vinculándolos, también, con el casework y las aportaciones de Mary Richmond. Después, recopilan los conocimientos del trabajo social comunitario y su aportación en la construcción de narrativas con colectivos. Por fin, completan el relato con la identificación de los puntos de encuentro entre la práctica narrativa y el trabajo social feminista.

El capítulo 2 es un extenso y detallado recorrido para describir los fundamentos epistemológicos y metodológicos de la práctica narrativa, para lo cual se analiza la contribución de la posmodernidad y el posestructuralismo a la misma. El capítulo está plagado de referencias de autores y autoras relevantes en la fundamentación de la práctica narrativa, cuyos saberes van siendo entrelazados por Martí y Pérez, creando un texto lleno de contenido, bien fundamentado y rico, muy rico, en matices. Se aprecia dominio de las fuentes relacionadas con el tema tratado. Las fuentes están actualizadas y tiene referencias internacionales.

En el capítulo 3 se presentan los principios de la práctica narrativa, en diálogo con los principios del trabajo social definidos en la FITS en Melbourne, Australia, en 2014. Previamente, se presenta el contexto histórico y el pensamiento filosófico de la práctica narrativa, conscientes de que los contextos y los modelos mentales condicionan los resultados por lo que, para dialogar, es necesario conocer dónde y cómo surgen las propuestas narrativas. A partir de aquí, se profundiza en los conceptos básicos: atención al contexto; inspiración interdisciplinar; visión social/interpersonal del conocimiento y la identidad; el lenguaje como eje central de la práctica; la multiplicidad de voces; el interés por lo que sí funciona; el valor del conocimiento local; la propia agencia personal; la flexibilidad en la duración de la asistencia; ser transparente; la práctica como colaboración; y, por último, la convicción de que el consultante, cliente, usuario, persona, se vea como centro del proceso. Este diálogo entre la práctica narrativa y el trabajo social lleva a los autores a mirar de nuevo conceptos clave del trabajo social como son: cliente/usuario - persona; diagnóstico; ayudar - asistir... y revisar, una vez más, la postura profesional.

El capítulo 4 define el espacio de la investigación: los objetivos, los límites o perímetros de la misma, centrando el foco en los contextos y metacontextos profesionales de cambio, 
optando por aquellos en los que se va a desarrollar la investigación y argumentando las opciones desde el prisma de la práctica narrativa.

El capítulo 5 relata el andamiaje metodológico del proceso de investigación. La elección del diseño metodológico; las técnicas empleadas; el guion de las entrevistas; las etapas del proceso y demás. Es un capítulo de lectura para aquellas compañeras y compañeros que estén realizando o vayan a realizar su tesis doctoral. De manera que se pone en valor su aportación al conocimiento científico en términos de posibilidad de réplica en otras investigaciones y su posible utilización en la práctica del Trabajo Social.

El capítulo 6 es el relato de los resultados obtenidos. Un relato entretejido con las aportaciones de las y los informantes de los grupos de discusión, encuestas y entrevistas en profundidad que sustentan la investigación. Los resultados y la discusión posterior se presentan agrupados en función de las técnicas empleadas. Así, en primer lugar, en los grupos de discusión se abordan temas claves para la profesión: la percepción de los servicios sociales por parte de los informantes y la identificación de ciertos chivos expiatorios como explicación de los problemas presentados. Así como los efectos que el sistema produce en los usuarios: la dependencia, la cronificación... Igualmente, se analiza la opinión en relación con el oficio del trabajo social, con el modelo de intervención actual. Por otra parte, en los grupos se plantea la percepción que los informantes tienen sobre la práctica narrativa: cómo la definen, qué ventajas e inconvenientes observan; con qué población o tipología de usuarios se podría aplicar; y qué se necesitaría para su implementación. En segundo lugar, y respecto a los datos obtenidos por medio de las encuestas, la obra recoge una representación de los resultados y un análisis del discurso en aspectos vinculados con la percepción de los profesionales en relación con las personas con las que interactúan: los problemas que les afectan, los sueños o propósitos que plantean, las historias dominantes, las relaciones, la influencia del contexto o los juicios normalizadores son algunas de las cuestiones abordadas. Por último, en tercer lugar, se presentan los resultados, análisis de datos y discusión del discurso de los entrevistados en las entrevistas en profundidad a "élites" o expertos en la práctica narrativa. En este momento se presentan algunos discursos que dan soporte a la discusión, hilando las voces de autores referentes de la práctica narrativa con las voces de las personas entrevistadas, a partir de la lectura de los extractos de sus aportaciones.

El capítulo 7 recoge la evaluación de la experiencia compartida entre profesionales de acción social y docentes, el ágora donde se ha gestado y desarrollado esta investigación. A partir de la misma, A. Martí y J.V. Pérez nos señalan los elementos clave para coconstruir el nuevo modelo de práctica social, que pasa por co-construir la práctica narrativa en el espacio gubernamental y dibujar los parámetros de un nuevo modelo de trabajo social desde la narrativa. Para ello hay que abordar temas vinculados con las relaciones de poder, la postura profesional, los cambios metodológicos necesarios para implementar este modelo y la supervisión o el aprendizaje desde la práctica.

Por fin, en el capítulo 8 Martí y Pérez nos muestras sus reflexiones finales, las conclusiones generales, la respuesta a las inquietudes que motivaron esta investigación: el malestar en las organizaciones de servicios sociales, la inquietud por buscar alternativas y la esperanza por reconectar a todos los agentes involucrados en la reconstrucción de sus vidas.

Estamos ante una obra que recoge un diálogo lleno de matices, cuyo objetivo ha sido la búsqueda de una alternativa de práctica profesional del trabajo social que genere la recuperación de relaciones más respetuosas entre las y los trabajadores sociales y las personas que acuden a los servicios. Una propuesta que vincula el trabajo social con la 
práctica narrativa, desde un cambio epistemológico que nos lleva a mirar desde otro lado y a construir otra realidad; todo ello con un objetivo claro: proponer una alternativa para responder a profesionales que demandan un cambio en la manera de gestionar sus prácticas. Esta obra plantea una visión despatologizante de las personas consultantes de los servicios sociales proponiendo una intervención social que presta atención a sus relatos y experiencias, en la que se reconozcan sus capacidades, sus habilidades y en la que puedan recuperar la confianza perdida en ellas mismas.

Ane Ferran Zubillaga y Cinta Guinot Viciano

Doctoras, trabajadoras sociales, y docentes de la Facultad de Ciencias Sociales y Humanas de la Universidad de Deusto 